\title{
The impact of climatic conditions of spring flood formation on hydrograph shape of the Desna River
}

\author{
Borys Khrystyuk, Liudmyla Gorbachova, Olga Koshkina \\ Ukrainian Hydrometeorological Institute, Prospekt Nauki 37,03028 Kyiv,Ukraine, e-mail: khryst@uhmi.org.ua, gorba- \\ chova@uhmi.org.ua, olga.koshkina@ukr.net
}

\begin{abstract}
Climatic factors are the most important of all the factors that influence the hydrograph shape of a river; this is because they are dynamic in space and time. The presence of hydrographs with a similar shape in long-term observation series of water runoff indicates that from time to time in the catchment of a river the same conditions of water runoff formation repeat. This is due to the cyclicity of climatic and - as a consequence-hydrological processes. The classification of hydrographs based on the similarity of their shapes on the Desna River (observation period 18852010) was carried out using the geometrical similarity criterion $(\rho)$ and the average Euclidean distance between values of hydrograph pairs $(\eta) .41$ classes of hydrographs, which included from 1 to 6 hydrographs, were obtained. Among them were determined 12 classes with low probability, 9 classes with medium probability and 20 classes with high probability. An analysis of the conditions of hydrograph formation for each of the identified classes was performed for the following factors: the sums of daily air temperatures and precipitation during the period of positive air temperature (from July) and the period of negative air temperatures, and also during the period of temperature transition through $0^{\circ} \mathrm{C}$ up to the peak discharges, index of depth of soil freezing, index of snow water equivalent, index of soil moisture content, and index of snowmelt. In general, hydrographs which are included in one class have similar climatic conditions to those of water runoff formation. However, in some cases, a combination of different values and dynamic factors can lead to the formation of similar hydrograph shapes.
\end{abstract}

Keywords: hydrograph shape, classification, spring flood, climatic factors

Submitted 11 May 2016, revised 22 August 2016, accepted 19 December 2016

\section{Introduction}

A spring flood is a typical feature of the hydrological regime of the Desna River. In this period the largest water discharges occur, and this can lead to catastrophic consequences. For this reason, the study of the conditions of spring flood formation and their influence on the hydrograph shape was important. The shape of the spring flood hydrograph is determined by many factors. Scientific publications (de Laat, Savenije 1992; Ramirez 2000; Vladimirov 2009; Wirosoedarmo et al. 2010) mainly emphasise the rainfall characteristics and catchment properties. The paper by Wirosoedarmo et al. (2010) says that hydrograph shape is strongly influenced by the nature of the rainfall, the length of the main stream slope, and the direction and shape of the watershed. Ramirez (2000) distinguishes two groups of main factors affecting hydrograph shape: rainfall characteristics and drainage characteristics. The time distribution of runoff (the shape of the hydrograph) is influenced by climatic, topographic and geological factors (de Laat, Savenije 1992). Vladimirov (2009) divided all the factors into four groups: climatic, geomorphological, floral and anthropogenic. Each group includes a number of factors that influence flood formation. Moreover, each factor consists of several components. Note that within the same river basin, geomorphological factors are timeconstant. Floral and anthropogenic factors can be regarded as time-constant, under the condition of the immutability of economic activities in a river basin. Therefore, it is climatic factors, which are characterised by significant variability, that determine the shape and volume of the river's spring flood hydrograph every year. Precipitation, temperature and evaporation are the most significant climatic factors.

Globally, a considerable number of scientific publications are devoted to the study of the influence of climatic factors on the hydrological regime of rivers. An example is Szalińska et al. (2014), who investigated the statistical properties of precipitation extremes during the flood event in 2010 in the Odra River Basin. They noted that a good understanding of the statistical properties of precipitation patterns and their hydrological consequences is essential for flood prediction and control, as well as for water management. Identification of extreme precipitation events is an important element in the assessment of hydrological hazards and their potential effects. However, research of 
the impact of climatic factors on the shape of hydrographs is not given proper attention, although, in some studies some interesting approaches can be found. Tennant (2011) analysed the influence of the precipitation phase on the hydrograph shape of mountainous watersheds. The objective method of diurnal hydrograph classification as an aid to exploring changes in the hydrological functioning of glaciered catchments over the ablation season was shown Hannah et al. (1999). Perkins and Jones (2008) studied the influence of climatic factors on the formation of storm hydrographs in small forested basins. It should be noted that nowadays the issue of the influence of climatic factors on the spring flood hydrograph shape of lowland rivers is hardly studied. Usually, for hydrological calculations and forecasting the unit hydrograph method and water balance method are used (WMO 2009). The unit hydrograph method gives good results in the study of storm hydrographs, but, at the same time, has a schematic representation hydrograph. More complex hydrological models (e.g., a "rainfall-runoff" model) use the method of water balance, which takes into account climatic factors and allows forecasting of not only the value of the maximum water discharge, but also the hydrograph shape. However, this approach requires detailed input data, which is not always available for a river catchment. In addition, the model of "rainfall-runoff" with lumped parameters operates well when there is on a river catchment a direct correlation between water runoff and precipitation at a weak dependence of evaporation against precipitation. However, Ukraine's territory is located in different geographical zones that are characterised by a variety of correlations between the elements of water balance (Gorbachova 2014b). Khrystyuk (2013) hypothesised that, on the assumption of similar shapes of hydrographs, the same conditions of formation of water runoff can occur due to the cyclicity of climatic and hydrological processes. However, Khrystyuk (2013) did not perform an analysis of climatic factors for each class of hydrograph, which were obtained for the Danube River. It was decided that this hypothesis should be applied on another river basin (the Desna) in order to confirm the impact of climatic factors on the hydrograph shape. Therefore, the objective of this paper is to analyse the spring flood hydrograph shapes of the Desna River for the 126-year period of observation based on the method of classifying hydrographs by the similarity of their shapes, and to study the climatic factors that influence them.

\section{The study area}

The Desna River flows through the territory of Ukraine and Russia (Fig. 1). It is the longest and second largest basin

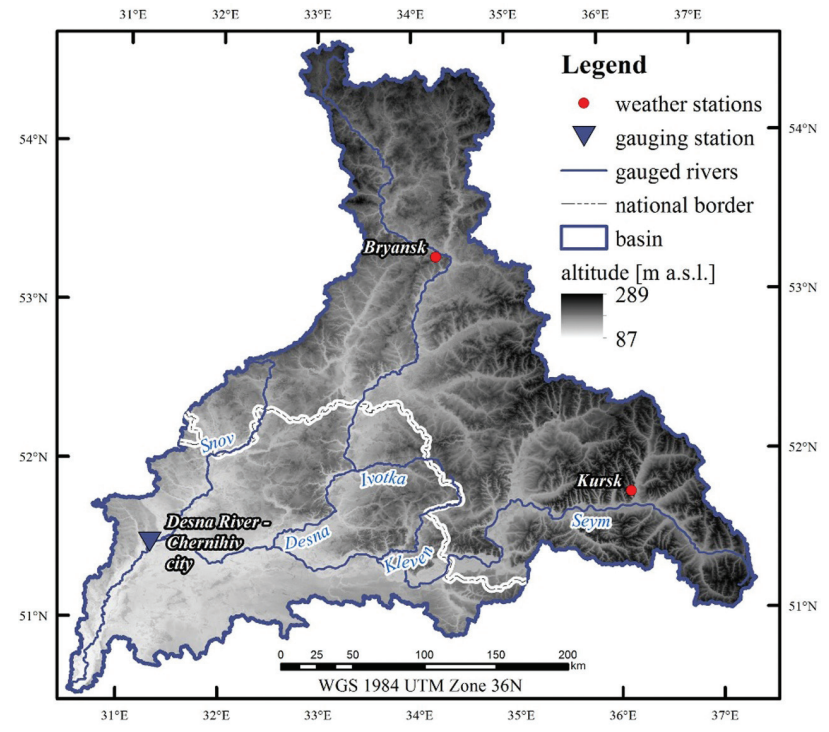

Fig. 1. Location of the Desna River basin

(after the Prypiat River) of the left tributary of the Dnipro River. The Desna River originates from the swamps that are located $9 \mathrm{~km}$ from the city of Yelnya (in the Smolensk region of Russia) at an altitude of $238 \mathrm{~m}$ above sea level. It flows mainly from the north-east to the south-west, to the Dnipro River, 10 miles north of the city of Kiev, at an altitude of $92 \mathrm{~m}$ above sea level. The total length of the river is $1126 \mathrm{~km}$ and the basin area is $88824 \mathrm{~km}^{2}$ (Koshkina, Hlotka 2013). The average water surface slope is $0.13 \%$. The length of the river on the territory of the Ukraine is $591 \mathrm{~km}$. The basin area on the territory of Ukraine is about $41330 \mathrm{~km}^{2}$ (nearly $46 \%$ of the total basin area).

The largest tributaries are the Snov, Seim and Oster. The coefficient of the river network density is equal to 0.21 . The density of the network of gullies and ravines ranges from 0.25 to $0.75 \mathrm{~km}$ per $1 \mathrm{~km}^{2}$. Absolute elevations of the surface basin are in the range of from $220 \mathrm{~m}$ to $100 \mathrm{~m}$, with the dominant figure being $125 \mathrm{~m}$ above sea level.

The Desna River has quite a wide floodplain, which floods almost every year, so the determining of the conditions of spring flood formation has a scientific and practical value. Bryansk and Chernihiv are major cities located on the Desna River. Water from the Desna River is the main source of water supply for the city of Kiev (Vishnevskiy 2000).

The climate is temperate continental in the Desna River basin. The coldest month is January, with mean monthly multi-annual air temperature of $-7.8^{\circ} \mathrm{C}$. The warmest month for the long-term observation period is July, with mean monthly multi-annual air temperature of $18.5^{\circ} \mathrm{C}$. The Desna River Basin is located in a zone of sufficient humidity. The multi-annual mean amount of precipitation per year within the basin is $570-620 \mathrm{~mm}$. 


\section{Methodology and data}

To operate with the observational data one must adhere to the conditions of homogeneity and stationarity of the members of a statistical series (WMO 2009). Therefore, in our studies (Gorbachova, Kolianchuk 2012; Koshkina, Gorbachova 2013) a complex analysis of long-term dynamics of hydrometeorological characteristics of the spring flood formation in the Desna River basin was carried out based on hydro-genetic methods and a statistical method. Methodological approaches to the assessment of the homogeneity and stationarity of hydrological observation series based on hydro-genetic methods was developed by Gorbachova (2014a), Gorbachova and Bauzha (2013).

To analyse the hydrograph forms of the Desna River, the method of classifying hydrographs by the similarity of their shapes (Khrystyuk 2013) was used. This method uses two independent criteria of similarity: the geometric similarity criterion $(\rho)$ and the criterion of the average Euclidean distance between the values of the two hydrographs $(\eta)$. Criteria $\rho$ and $\eta$ are used in meteorological research to classify synoptic processes (Bagrov 1969; Martazinova 2005). The validity of the use of the criteria $\rho$ and $\eta$ for hydrograph classification cannot be doubted because the difference between the observations of the atmosphere in a given time period in a respective territory, and water runoff observations of the river at a gauging station, is just that in the first case we are dealing with multidimensional fields, and the second case with the a one-dimensional field. Thus, the adaptation of $\rho$ and $\eta$ criteria for their use for the purpose of hydrograph classification does not require much effort. The selection of any river hydrograph for the entire observation period can be represented as a matrix $Q$ with elements $Q_{i j}$, which correspond to the value of water discharge in the $i$ date of the $j$ year:

$$
Q=\left|\begin{array}{cccccc}
Q_{11} & Q_{12} & \ldots & Q_{1 j} & \ldots & Q_{1 N} \\
Q_{21} & Q_{22} & \ldots & Q_{2 j} & \ldots & Q_{2 N} \\
\ldots & \ldots & \ldots & \ldots & \ldots & \ldots \\
\ldots & \ldots & \ldots & \ldots & \ldots & \ldots \\
Q_{K 1} & Q_{K 2} & \ldots & Q_{K j} & \ldots & Q_{K N}
\end{array}\right|
$$

where $i=1,2, \ldots, K$-dates; $j=1,2, \ldots, N$-years.

Criterion $\rho$ allows for the estimating of the geometric similarity of the two hydrographs by values of deviations compared to the averaged hydrograph for the long-term period:

$$
\rho=\frac{n_{+}-n_{-}}{n_{+}+n_{-}}
$$

where $n_{+}$- number of dates in which the deviation marks coincide; $n_{-}-$number of dates in which the deviation marks are opposite. The value of the criterion is within $-1 \leq \rho \leq 1$. Criterion $\eta$ is the average Euclidean distance between the values of two hydrographs:

$$
\eta=\frac{1}{K} \cdot \sqrt{\sum_{i=1}^{K}\left(Q_{i j}-Q_{i l}\right)^{2}}
$$

where $Q_{i j}$ and $Q_{i l}$ - the value of water discharge in the $i$ date of the hydrographs $j$ and $l$ years.

The value of $\eta$ criterion is above or equal to 0 .

Criteria $\rho$ and $\eta$ for each pair of hydrographs are calculated as a square matrix of size $N \times N$. The elements of the main matrix diagonal of the criterion $\rho$ equal 1 , and criteria $\eta-0$.

When adding hydrographs of $j$ and $l$ years to one class, we have the following three situations:

- The value of $\rho$ and $\eta$ criteria is simultaneously optimal for the hydrograph of $j$ year against the hydrograph of $l$ year, and vice versa. In this situation hydrographs have a good similarity;

- The value of $\rho$ and $\eta$ criteria is simultaneously optimal for the hydrograph of $j$ year against the hydrograph of $l$ year, and, vice versa - it is not. In most such situations hydrographs have a good or satisfactory similarity. It is necessary to perform searches for years for which the $\rho$ and $\eta$ criteria are both closest to their optimal values in the case of unsatisfactory similarity;

- The value of $\rho$ criteria for hydrograph of $j$ year is optimal against one year, and the value of $\eta$ criteria is against another. In this case it is also necessary to search for years for which the criteria $\rho$ and $\eta$ are simultaneously closest to their optimal values.

Calculations of matrices of $\rho$ and $\eta$ criteria, as well as the determination of years with maximum and minimum values of $\rho$ and $\eta$ criteria, are carried out using the "Analog" software that was developed by Khrystyuk (2013).

This method allows for the detecting of hydrograph classes that have a similar shape in a long-term observation series of water runoff. This indicates that from time to time in the catchment of the river similar conditions of water runoff formation repeated due to the cyclicity of climatic and - as a consequence - hydrological processes.

The shape of a spring flood hydrograph is determined by the variations of the following characteristics: air temperature, precipitation, depth of soil freezing, soil moisture content and snow water equivalent. However, among all these data the long-term observation series in the Desna River basin contain only air temperature and precipitation. Observations of the depth of soil freezing and snow water equivalent have gaps, and begin in the 1950-60s. How- 
ever, a water runoff observation on the Desna River, at Chernihiv City water gauging station, was begun in 1885 . Moreover, the highest floods are observed in the first half of the twentieth century. Soil moisture content is measured in some years in the autumn, and in the others in the spring. Based on the above, for the analysis of the spring flood hydrograph formation conditions of the Desna River, sums of daily air temperatures and precipitation during the positive period (from July) and negative temperatures were used; also, during the period of the temperature transition through $0^{\circ} \mathrm{C}$ before the spring flood peak, the following were used: the index of depth of soil freezing, index of snow water equivalent, index of soil moisture content, and index of snowmelt, which are calculated by the following formulas:

The index of depth of soil freezing (FDSI) is defined by the formula:

$$
F D S I=\frac{\sum T^{-}}{\sum P^{-}}
$$

where $\sum T^{-}$and $\sum P^{-}$are, respectively, the sums of daily air temperatures and precipitation during the period of negative temperature.

The index of snow water equivalent $(S W E I)$ is defined as follows:

$$
S W E I=\sum \mathrm{T}^{-} \cdot \sum P^{-}
$$

The index of soil moisture content $(S M C I)$ is defined by the formula:

$$
S M C I=\frac{\sum P^{+}}{\sum T^{+}}
$$

where $\sum T^{+}$and $\sum P^{+}$are, respectively, the sums of daily air temperatures and precipitation during the period of positive temperatures (from July).

The index of snowmelt (SMI) is defined by the formula:

$$
S M I=\sum P_{f}^{+} \cdot \sum T_{f}^{+}
$$

where $\sum T_{f}^{+}$and $\sum P_{f}^{+}$are the sums of daily air temperatures and precipitation during the period of the temperature transition through $0^{\circ} \mathrm{C}$ before the spring flood peak.

The observed data from the Desna River - Chernihiv City water gauging station for the period 1885-2010 were used for research. The Desna River - Chernihiv City water gauging station city is the outfall station of the Desna River Basin. Moreover, the observed data at Bryansk and Kursk meteorological stations were also used - they have the longest observation series of air temperature and precipitation (respectively 1936-2010 and 1896-2010). Unfortunately, these observed data have gaps due to military action. Also, these meteorological stations are located in the upper part of the Desna and Seim rivers (Fig. 1), which are the main areas of the water runoff formation of the Desna River. The observed data from Bryansk meteorological station were used to confirm tendencies in the dynamics of the factors that form the hydrographs.

\section{Results}

Analysis of the daily maximum, average and minimum water discharges of the Desna River showed that the hydrographs have a quite simple shape, with a clearly distinct spring flood (Fig. 2). The greatest water content was observed from early September to mid-June, which corresponds to the spring-summer flood period. The flood peak is observed in the middle and end of April, except for the highest floods. For these, in some years a flood peak can be observed in early May. Summer-autumn low flow is characterised by a lack of rain floods.

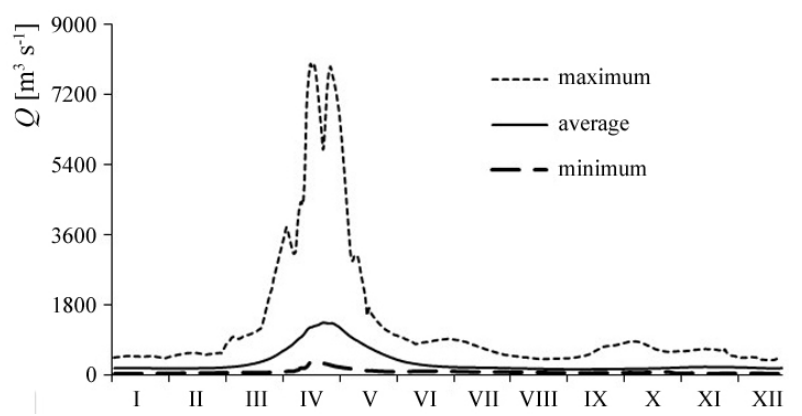

Fig. 2. Daily discharges on the Desna River - Chernihiv City water gauging station for the period 1885-2010

Despite the simple shapes of the Desna River hydrographs, it was found that the deviations of some hydrographs from the average hydrograph (for the period 18852010) vary quite widely. This is explained by the quite different climatic conditions of spring flood formation in each year. Thus, according to the method of classification of hydrographs with a similar shape, among 126 hydrographs (Desna River - Chernihiv city) 41 class were found; these included from 1 to 6 hydrographs. Among them 12 classes with low probability, 9 classes with medium probability and 20 classes with high probability were identified. Classes of hydrographs are related to each other by the similar characteristics of the main phases of water regime: stability and the height of summer-autumn and winter low flow, the start and end dates, duration, height, and the intensity of the increase and decrease of the spring-summer flood. It should be noted that different classes of hydrographs have different degrees of similarity depending on the ratio of criteria $\rho$ and $\eta$. For example, hydrographs with a high probability in Figure 3 have a satisfactory similarity (left) and a good similarity (right). 

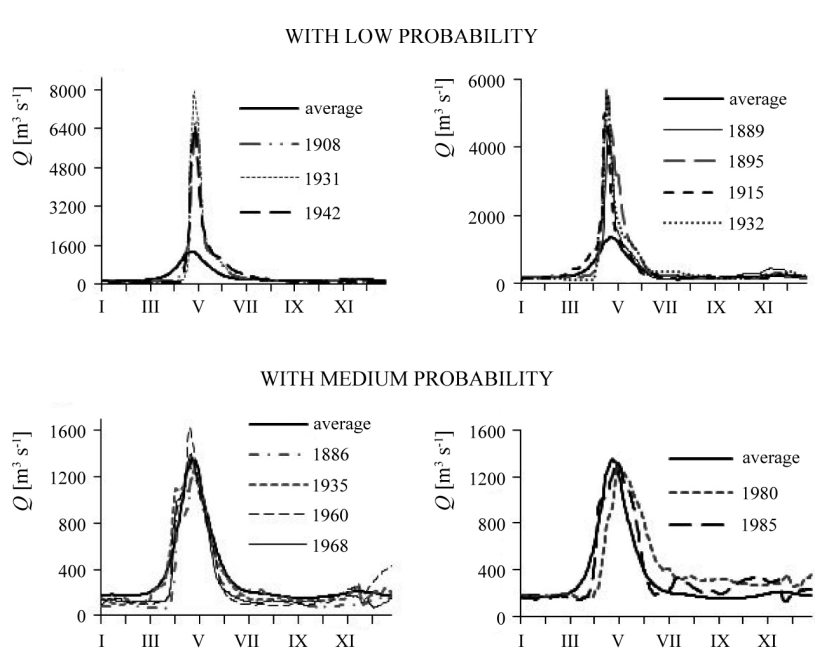

WITH HIGH PROBABILITY
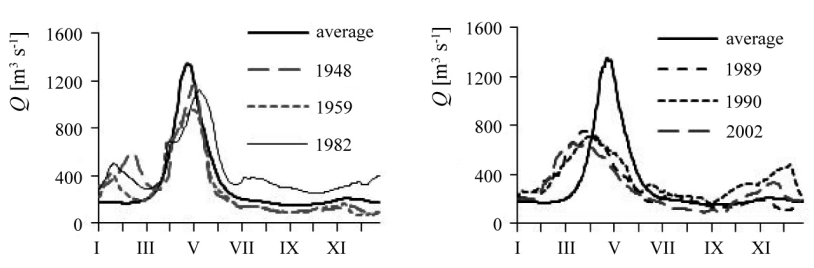

Fig. 3. Hydrograph classes with a similar shape

So, we can assume that hydrographs that are included in the same class have similar climatic conditions of water runoff formation. The analysis of the graphs that characterise the conditions for the formation of hydrographs with low probability and relate to the same class showed that they have common features (Fig. 4). The analysis was carried out only for floods in 1908 and 1931, because observed data for 1942 are absent due to military action. Storage curves of air temperature, precipitation and snow water equivalent have a good similarity of dynamics and values.

Dates of the start of the flood, as well as the depth of soil freezing at the beginning of the flood coincide. However, significant precipitation in summer and autumn and, consequently, greater soil moisture and also higher air temperature and precipitation in the period of the beginning of floods formed higher flood peak discharge in 1931 $\left(7940 \mathrm{~m}^{3} \mathrm{~s}^{-1}\right)$ compared with flood peak discharge in 1908 $\left(6860 \mathrm{~m}^{3} \mathrm{~s}^{-1}\right)$.

The analysis of all classes of hydrographs has revealed common features of conditions of their formation, depending on the probability of exceedance (Table 1). The formation of catastrophic and outstanding spring floods in the Desna River Basin occurs in the conditions of a cold autumn-winter period, with a significant accumulation of snow water equivalent in the river catchment and a large depth of soil freezing.

In the spring the dates of air temperature transition through $0^{\circ} \mathrm{C}$ occur in the first half of April. At the same
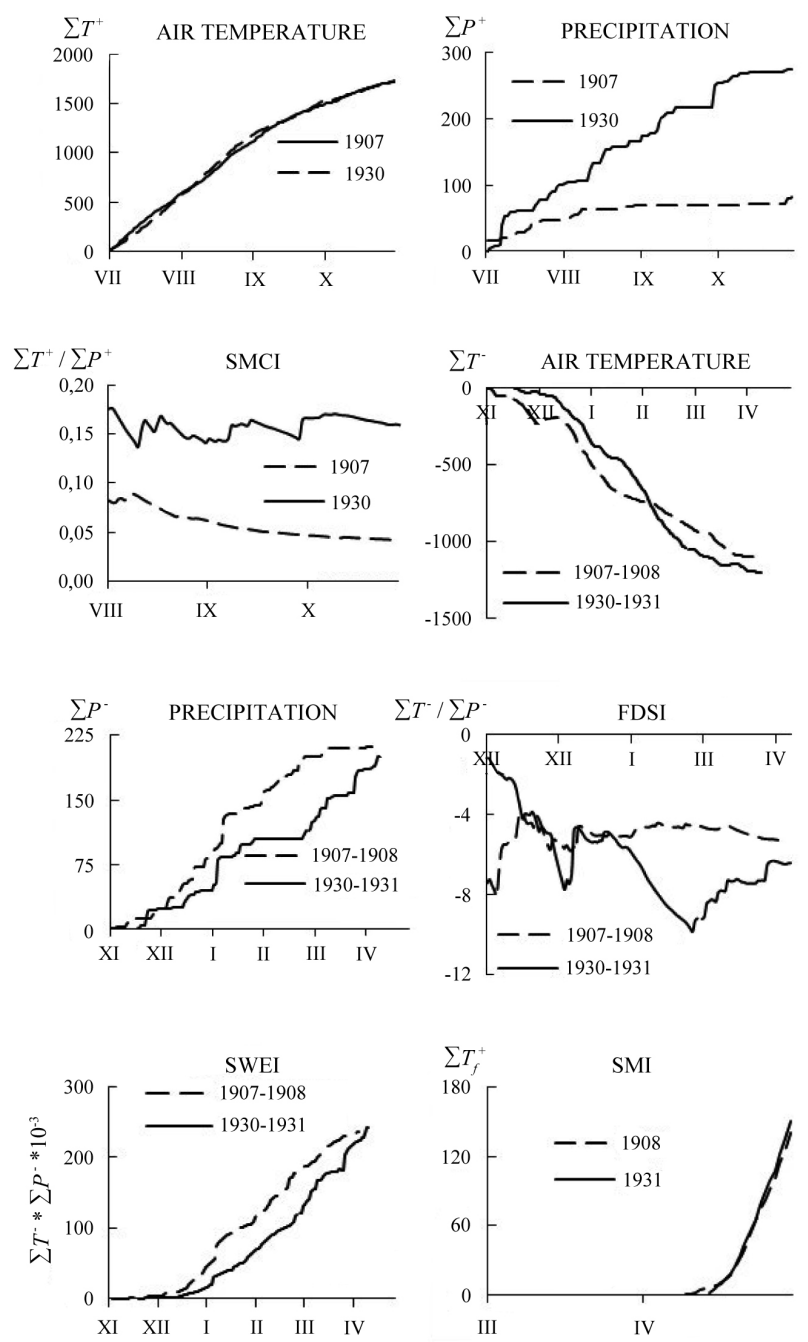

Fig. 4. Dynamics of the main factors of the spring flood formation of the Desna River with low probability, according to the data from the Kursk meteorological station

time, there is a rapid air temperature increase that causes intense snowmelt, which may be increased by precipitation. Typically, the air temperature, precipitation and soil moistening in the summer-autumn period do not significantly influence the spring flood formation of the Desna River. However, these characteristics have significant influence on the formation of catastrophic floods. It was found that for the analysis of the conditions of spring flood formation, it is not enough to have information only on the values of factors. It is equally important to consider the dynamics of factors, especially in the period before the spring flood.

The analysis of factors that form the hydrographs with medium probability showed that in some years, their values coincide with the values of the factors that shape the hydrographs with low probability. However, an outstanding flood was not formed. Analysis of the dynamics of factors revealed features of the formation of hydrographs with medium probability. Usually these hydrographs are formed at lower values of the sums of daily air tempera- 
Table 1. The value of the factors of spring flood formation on the Desna River with the various probability hydrograph shapes (according to the Kursk meteorological station); note: in the denominator are the values observed in certain years

\begin{tabular}{|c|c|c|c|}
\hline \multirow{2}{*}{ Factors } & \multicolumn{3}{|c|}{ The hydrograph shape with probability } \\
\cline { 2 - 4 } & low & medium & high \\
\hline$\sum T^{+},{ }^{\circ} \mathrm{C}$ & $1500-1950$ & $1500-1700$ & $1500-1700 / 2200$ \\
\hline$\sum P^{+}, \mathrm{mm}$ & $150-400$ & $150-330$ & $0.10-0.16$ \\
\hline$S M C I$ & $1.10-0.24$ & $0.10-0.20$ & $-(300-700) /-1100$ \\
\hline$\sum T^{-},{ }^{\circ} \mathrm{C}$ & $-(700-1350)$ & $-(400-700) /-1350$ & $85-170 / 200-220$ \\
\hline$\sum P^{-}, \mathrm{mm}$ & $180-300$ & $130-200 / 350$ & $-(3-6) /-10$ \\
\hline$F D S I$ & $-(10-15) /-6$ & $-(4-6)$ & $(50-100) \cdot 10^{-3} /(160-190) \cdot 10^{-3}$ \\
\hline$S W E I$ & $(100-300) \cdot 10^{-3}$ & $(70-120) \cdot 10^{-3} / 240 \cdot 10^{-3}$ & end of February, March \\
\hline $\begin{array}{c}\text { temperature } \\
\text { transition through }\end{array}$ & first half of April & second half of March & $200-370$ \\
\hline $0^{\circ} \mathrm{C}$ & $140-225$ & $170-300 / 400$ & $20-60 / 120$ \\
\hline$\sum T_{f}^{+},{ }^{\circ} \mathrm{C}$ & $30-75 / 90$ & $25-60 / 90$ & $(20-220) \cdot 10^{-2} / 600 \cdot 10^{-2}$ \\
\hline$\sum P_{f}^{+}, \mathrm{mm}$ & $(120-170) \cdot 10^{-2}$ & $(30-100) \cdot 10^{-2} /(220-300) \cdot 10^{-2}$ & \\
\hline$S M I$ & & &
\end{tabular}

tures, precipitation during periods of negative temperatures, and also snow water equivalent compared to the conditions of the formation of hydrographs with low probability. At high values of the sums of daily air temperatures during the period of negative temperatures smaller values of snow water equivalent are observed; this does not lead to the formation of hydrographs with low probability. At high values of the sums of daily air temperatures during the period of negative temperatures and snow water equivalent in the period before the beginning of the spring flood, higher values of air temperature are observed and the date of the temperature transition through $0^{\circ} \mathrm{C}$ is in the second half of March. This causes a gradual melting of snow and the snowmelt period is increased, thereby reducing values of peak discharge. The low level of soil moisture in the catchment also contributes to this. Such conditions were observed in the flood of 1968, which had all the makings of becoming an outstanding flood, but in fact did not do so (Fig. 5).

The conditions of hydrograph formation with high probability are varied, but generally they are formed at low values of snow water equivalent. At the same time, high values of the sums of daily air temperatures during periods of negative temperatures and depth of soil freezing can be observed. The date of the temperature transition through $0^{\circ} \mathrm{C}$ is in March. Such conditions are typical of the flood in 1902. Thaws can be observed in the case of significant snow water equivalent; these were formed during the autumn-winter period. This leads to the formation of winter floods (January-February) and, consequently, decreases values of flood peak discharge (Fig. 3). Sometimes a flood can begin at the end of January, in the conditions of low values of snow water equivalent, and early air temperature transition through $0^{\circ} \mathrm{C}$ (Fig. 3, 6).
It was found that the formation conditions may vary for some classes with similar forms of hydrograph. The formation of similar shapes of hydrograph is a result of a combination of factors. For example, the flood in 1910 was formed with low values of the sums of daily air temperatures during the period of negative temperatures $\left.-611^{\circ} \mathrm{C}\right)$ and snow water equivalent $\left(84 \times 10^{-3}\right)$. For the flood in 1996 the sums of daily air temperatures during the period of negative temperatures and snow water equivalent were $-1122^{\circ} \mathrm{C}$ and $227 \times 10^{-3}$ respectively. However, for the flood in 1910 the air temperature transition through $0^{\circ} \mathrm{C}$ occurred on 14 March and for the flood 1996 this was on 31 March.

At the same time, in 1910 the snowmelt period had quite a significant amount of precipitation $\left(\sum P_{f}^{+}=93 \mathrm{~mm}\right)$ and in 1996 this value was only $27 \mathrm{~mm}$. Due to such conditions, in 1910 intensive snowmelt $\left(S M I=257 \times 10^{-2}\right)$ was observed, while in 1996 this was slow $\left(S M I=53 \times 10^{-2}\right)$. So, in some cases a combination of different values and dynamic factors can lead to the formation of similar shapes of hydrographs. Thus, the exact conditions before a flood are essential.

The proposed approach of the classification of hydrographs by the similarity of their shapes with subsequent analysis of the climatic factors in each class of hydrograph can significantly expand knowledge about the conditions of hydrograph formation with different probabilities of exceedance. This approach allows for features of water runoff formation of the river within groups with various hydraulicity to be taken into account, as opposed to the traditional statistical method. In a statistical method, for the purpose of division into groups of hydraulicity (high water, medium and low water) the shape of hydrograph is not considered. At the same time, there are various forms 

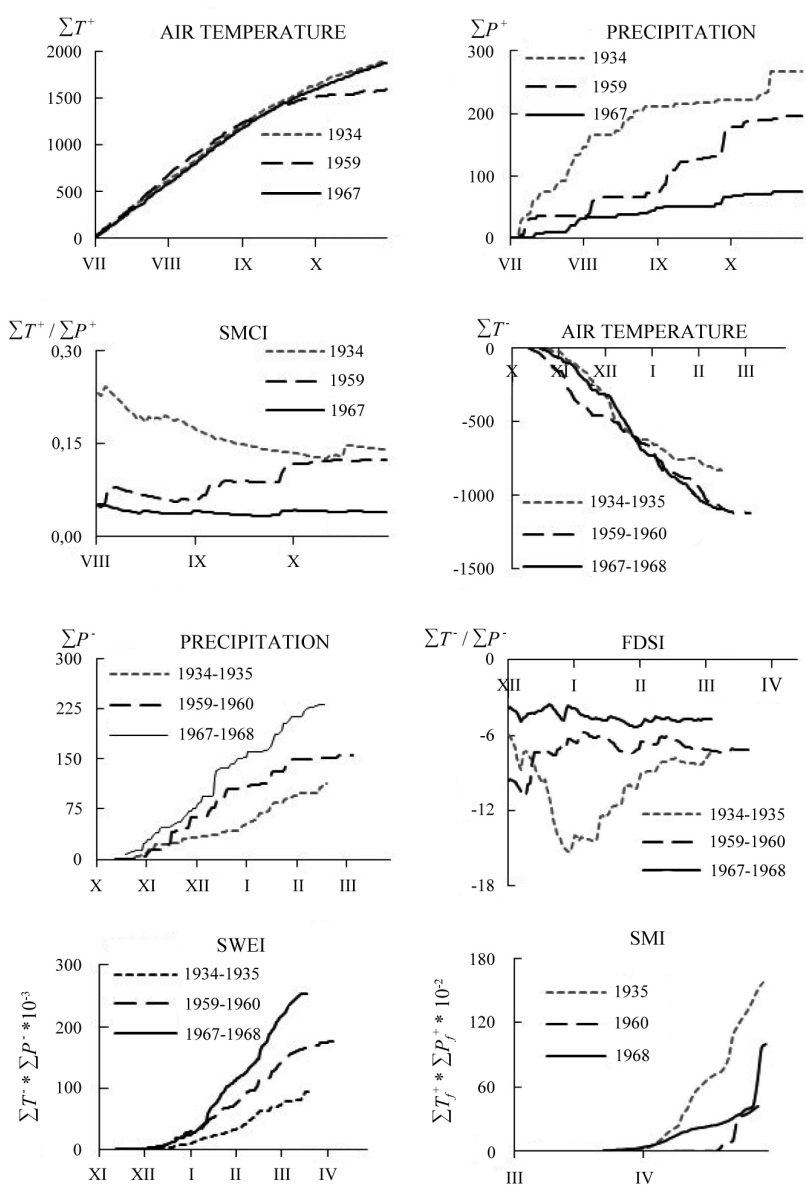

Fig. 5. Dynamics of the main factors of the spring flood formation of the Desna River with medium probability, according to data from the Kursk meteorological station

of hydrographs in each group of hydraulicity (Fig. 3). The consideration of hydrograph shapes has important practical value - for example, for the operation of reservoirs, industrial and municipal water management, the smooth functioning of water transport, flood proofing, hydrological forecasting. Analysis of climatic factors in hydrograph classes confirms the hypothesis that similar shapes of hydrographs are formed in similar climatic conditions. This is due to the cyclicity of climatic and hydrological processes. However, there are exceptions when the combination of various factors form similar hydrograph shapes. In addition to quantitative indicators of climatic factors, it is equally important to consider their dynamics, especially in the period before the spring flood. These obtained results demonstrate the relevance of the deterministic approach to the study of water runoff of rivers. Analysis of climatic factors on limited data, namely on the basis of indices reflecting the moisture conditions, evaporation, snowmelt, and other factors, allows for the study of the watersheds of rivers that do not have a developed observation network.

In contemporary long-term hydrological forecasting, the hydrograph shape is predicted in a simplified schemat-
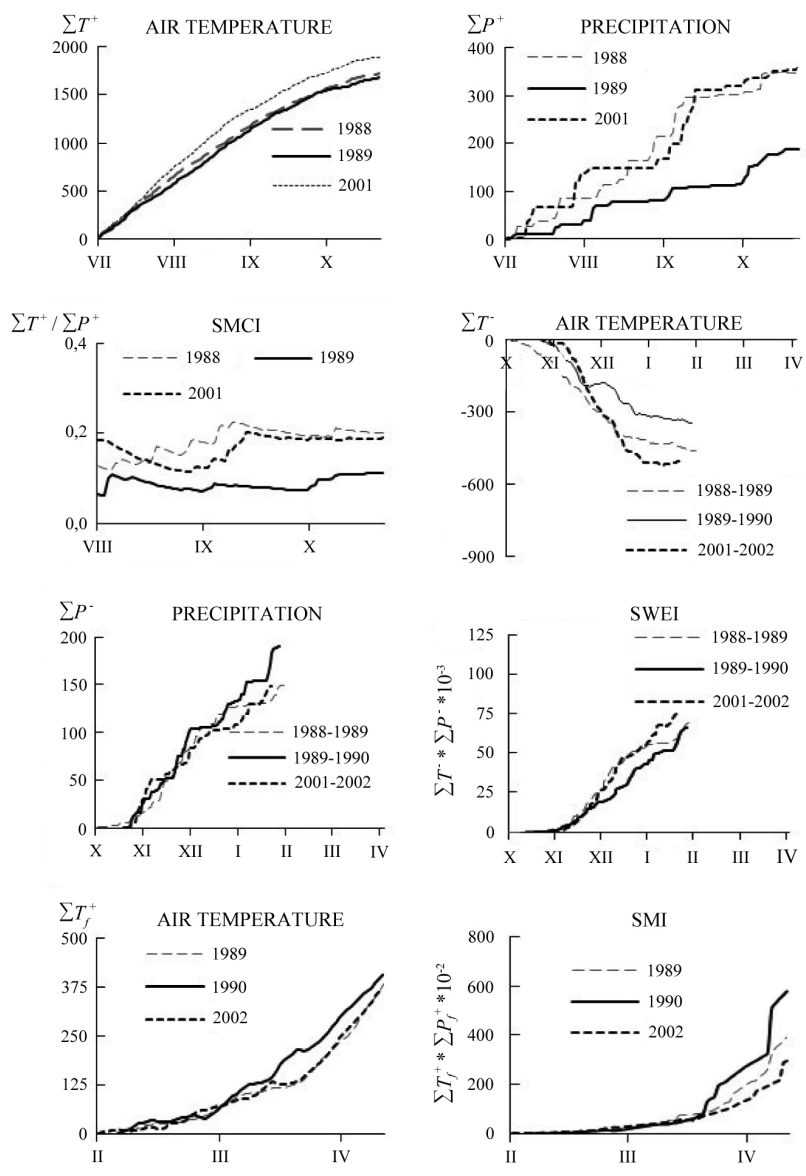

Fig. 6. Dynamics of the main factors of spring flood formation of the Desna River with high probability, according to data from the Kursk meteorological station

ic form on the basis of hydrological information (maximum discharges, depth of runoff, the duration of a flood rising, time of concentration), that is, without taking into account climatic factors. Thus, the proposed methodical approach to the classification of hydrographs and analysis of climatic factors will allow for the improvement of results of long-term forecasting. Based on the analysis of the climatic conditions, for example, in the autumn-winter period, it will be possible to predict the shape of the hydrograph using an analogue, which is selected according to a particular hydrograph class. The implementation of this hypothesis could be the next step of the study.

\section{Conclusion}

126 hydrographs of the Desna River in the city of Chernihiv were classified into 41 classes, which include from 1 to 6 hydrographs according to the similarity of their shapes on the basis of two criteria of similarity. The climatic conditions of the formation of Desna River hydrographs are very diverse every year, hence the considerable number of classes. 
Generally, hydrographs that are included in the same class have similar climatic conditions of water runoff formation. This demonstrates the repeatability of conditions of water runoff formation due to cyclical processes. At the same time, in some cases a combination of different values and dynamic factors can lead to the formation of similar forms of hydrographs. The most important factors that influence the form of hydrographs are temperature, snow water equivalent and snowmelt conditions.

The results enable the extension of knowledge about the conditions of the water runoff formation of the river and may be important for hydrological calculations and long-term forecasting.

\section{Bibliography}

Bagrov N.A., 1969, Classification of synoptic situations, (in Ukrainian), Meteorology and Hydrology, 5, 3-12

de Laat P.J.M., Savenije H.H.G., 1992, Factors affecting hydrograph shape, Hydrology, Delft, 89-91

Gorbachova L.O., 2014a, Methodical approaches to the assessment of the homogeneity and stationarity of hydrological observation series, (in Ukrainian), Hydrology, Hydrochemistry and Hydroecology, 1 (32), 22-31

Gorbachova L.O., 2014b, Spatial distribution of links between the elements of the water balance catchments of Ukraine, (in Ukrainian), Ukrainian Geographical Journal, 2, 17-21

Gorbachova L., Bauzha T., 2013, Complex analysis of stationarity and homogeneity of flash flood maximum discharges in the Rika River basin, Energetika, 59 (3), 167-174

Gorbachova L.O., Kolianchuk O.V., 2012, Long-term dynamics of the main hydrometeorological characteristics of spring flood in the Desna River basin, [in:] Water Resource and Wetlands Conference proceedings, Tulcea, Romania, 174-179

Hannah D.M., Gurnell A.M., McGregor G.R, 1999, A methodology for investigation of the seasonal evolution in proglacial hydrograph form, Hydrological Processes, 13 (16), 2603-2621

Koshkina O.V., Gorbachova L.O., 2013, Hydro-genetic research method of the main factors of the spring flood in the Desna River Basin, $11^{\text {th }}$ annual International Conference of Young Scientists on Energy Issues, Cyseni, Kaunas, Lithuanian Energy Institute, IX618-IX631
Koshkina O.V., Hlotka D.V., 2013, Spatial distribution of spring flood hydrometeorological characteristics in the Desna River basin using GIS, (in Ukrainian), Proceedings of Ukrainian Hydrometeorological Institute, 264, 34-43

Khrystyuk B.F., 2013, The technique of the classification of river hydrographs by criteria of analogy, (in Ukrainian), Hydrology, Hydrochemistry and Hydroecology, 3 (30), 15-20

Martazinova V.F., 2005, The classification of synoptic patterns by method of analogs, Journal of Environmental Science and Engineering, 7, 61-65

Perkins, R.M., Jones J.A., 2008, Climate variability, snow, and physiographic controls on storm hydrographs in small forested basins, western Cascades, Oregon, Hydrological Processes, 22, 4949-4964, DOI: 10.1002/hyp.7117

Ramirez J.A., 2000, Prediction and modeling of flood hydrology and hydraulics, [in:] Inland flood hazards: human, riparian and aquatic communities, E. Wohl (ed.), Cambridge University Press, 293-333

Szalińska W., Otop I., Tokarczyk T., 2014, Precipitation extremes during flooding in the Odra River Basin in May-June 2010, Meteorology Hydrology and Water Management, 2, 13-20

Tennant C.J., 2011, The influence of precipitation phase on hydrograph form: an investigation of twelve tributaries to the Salmon River, Idaho, M.S. thesis, Idaho State University, 89 pp.

Vishnevskiy V.I., 2000, Rivers and reservoirs of Ukraine. Condition and use, (in Ukrainian), Monograph, Vipol, 376 pp.

Vladimirov A.M., 2009, The factors determining occurrence of the high flow and highest water level during a flood, (in Russian), Proceedings of the Russian State Hydrometeorological University. A theoretical research journal, 9, 22-39

Wirosoedarmo R., Haji A., Tunggul Sutan, Pramesti E.M., 2010, Study on form, drainage network, and watershed hydrograph by using SIMODAS (case study on Sabu Island - Nusa Tenggara Timur), Jurnal Teknologi Pertanian, 11 (2), 123-130

WMO, 2009, Guide to hydrological practices. Volume II: Management of water resources and application of hydrological practices, WMO No 168, Geneva, available at: http:// www.whycos.org/chy/guide/168_Vol_II_en.pdf (data access 06.05 .2016 